Extended Abstract

\title{
Emerging Web-Life - A Marxian Perspective
}

\author{
László Ropolyi \\ Department of History and Philosophy of Science, Eötvös University, H-1518 Budapest Pf. 32 \\ Hungary
}

E-Mail: ropolyi@caesar.elte.hu

Tel.: +36-1-372- 2949; Fax: +36-1-372-2924

Accepted:

\section{Introduction}

Human existence is being transformed. Its structure, many thousand years old, seems to be changing: built on the natural and the social, there is a third form of existence: web-life. Man is now the citizen of three worlds, and its nature is being formed by the relations of natural, social and weblife. We regard as our main goal the study of web-life which developed as the result of internet use.

\section{Emerging Web-Life}

In order to study the mostly unknown context of web-life it seems to be useful to examine the nature of human existence, transformed through Internet use and the consequences of the changes. Social scientists like Castells [1], Wellman and Haythornthweait [2], or Fuchs [3] often characterize the consequences of the Internet use as pure social changes, including all kinds of changes into the social ones and disregard the significance of more comprehensive changes. We focus on the latter.

While using the Internet, all determining factors and identity forming relations change which had a role in the evolution of mankind from the animal kingdom and in the process of the development of society. We can identify tool use, language, consciousness, thought as well as social relationships as the most decisive changes in the process of becoming human and in the formation of web-life which developed as a result of Internet use.

The simultaneous transformations of animal tool and language use, animal consciousness and thought as well as social relationships and the series of interwoven changes led to the evolution of humans and to the development of culture and society. Nowadays, the robust changes in the same areas are also simultaneous. They point into one direction intensifying each other and induce an 
interconnected series of changes. Te quantity of the changes affecting the circumstances of human existence results yet again in the qualitative transformation of the circumstances of existence: this is the process of the development of web-life.

The material circumstances of tool making and tool use lose their significance and the emphasis is now on the most essential part of the process: interpretation. A crucial part of tool making is the interpretation of an entity in a different context, as different from the given (such as natural entities) and in this "technological situation" its identification as a tool. During Internet usage, individual interpretations play a central role in the process of creating and processing information on different levels and in the information technologies that are becoming dominant. At the same time the material processes that provide the conditions of interpretation are to a large extent taken care of by machines. Hermeneutics takes the central role of energetics in the necessary human activity of reproducing human relations.

The human double (and later multiple) representation strategy developed from the simpler strategies of the representation characteristic of wildlife led to language, consciousness, thought and culture. Double representation (I can regard an entity both as "itself" and "something else" at the same time) is a basic procedure in all these processes - and in tool making as well - and an indispensable condition of their occurrence. The use of the Internet radically transforms the circumstances of interpretation. On the one hand, it creates a new medium of representation, in which - as in some sort of global "mind" - the whole world of man is represented repeatedly. On the other hand, after the ages of orality and literacy it makes it possible basically for all people to produce and use in an intended way the visual representation of their own world as well. Virtuality and visuality are determining characteristics of representation. We are living in the process of the transformation of language, speech, reading and writing, memory and thought.

"Traditional" human culture is created through the reinterpretation of the relations "given by nature", it materializes through their perpetual transformation and it becomes a decisive factor in the prevailing social relations. Cyber-cultural practices of the citizens of the web is now directed at the revaluation of social relations, and as a result of their activities a cyber, web or Internet-cultural system of relations is formed, which is the decisive factor in the circumstances of web-life.

The basically naturally given communities of animal partnership were replaced by the human structure of communities which was practically organized as a consequence of the tool use based indirect, and language use based direct communicative acts. However, the control over communicative situations can be monopolized by various agents: as a result it is burdened with countless constraints. The nature of the communities that come into existence under these circumstances can become independent from the aspirations of the participants: various forms of alienation and inequality can be generated and reproduced in the communities. The citizen of the web who engages in communication reinterprets and transforms communicative situations; above all, he changes power relations in favor of the individual: the citizen of the web can have full powers over his own communicative situations.

\section{Conclusions}

Society is a system of relationships which develops from, and is built on the natural sphere. Weblife is a system of relationships which develops from, and is built on the social sphere. Man now is not the citizen of two worlds but three: he is the inhabitant of nature, society and web-life. 


\section{References}

1. Castells, M. The Rise of The Network Society, 2nd ed..; Blackwell: Oxford, England, 2000.

2. Wellman, B.; Haythornthweait, C. eds., The Internet in Everyday Life, Blackwell: Oxford, England, 2002.

3. Fuchs, C. Internet and society. Social theory in the information age, Routledge: London, New York, England, USA, 2008.

(C) 2015 by the authors; licensee MDPI and ISIS. This abstract is distributed under the terms and conditions of the Creative Commons Attribution license. 